\title{
Fatty Acid Composition as a Guide to the Classification of Selected Genera of Yeasts Belonging to the Endomycetales
}

\author{
By BENNIE C. VILJOEN, * JOHAN L. F. KOCK AND \\ PIETER M. LATEGAN \\ Department of Microbiology, University of the Orange Free State, PO Box 339, \\ Bloemfontein 9300, South Africa
}

(Received 6 January 1986; revised 20 March 1986)

Gas chromatography was used to determine the long-chain fatty acid composition of 33 strains representing 17 genera of the Saccharomycetaceae, Endomycetaceae, Metschnikowiaceae and Saccharomycodaceae. The similarities between the strains were calculated on the basis of fatty acid composition, resulting in three groups. Group I strains contained oleic acid (C18:1) as the major fatty acid, while group II strains had substantial proportions of both oleic acid and linoleic acid $(\mathrm{C} 18: 2)$. Strains of group III were characterized by a high percentage of palmitoleic acid (C16:1). The one strain of Metschnikowia reukaufii studied fell within the range of variation of group II, but it contained a slightly higher proportion of palmitoleic acid than the other strains in this group.

\section{INTRODUCTION}

Lipid analyses have been successfully used to determine and classify various yeasts (Gangopadhyay et al., 1979; Gunasekaran \& Hughes, 1980; Kaneko et al., 1976; Moss et al., 1982). Recently a simple and rapid method for estimating the cellular long-chain fatty acids of yeasts was established in our laboratory (Kock et al., 1985). In this paper the cellular long-chain fatty acids of 33 strains representing 17 selected genera of the families Saccharomycetaceae, Endomycetaceae, Metschnikowiaceae and Saccharomycodaceae are described to test the taxonomic value of this phenotypic character.

\section{METHODS}

Strains. Cultures were obtained from Professor J. P. van der Walt, Pretoria, South Africa (CSIR-Y) and the Centre of Biology, Gulbenkian Institute of Science, Oeiras, Portugal (IGC). The names used are those used by the culture collection of origin. The assignment to families is according to Von Arx (1981).

Saccharomycetaceae: Saccharomycopsis capsularis CSIR-Y447, CSIR-Y651; Williopsis saturnus CSIR-Y17; Clavispora lusitaniae CSIR-Y484; Schwanniomyces occidentalis CSIR-Y937, CSIR-Y936, CSIR-Y938; Schwanniomyces persoonii CSIR-Y285; Schwanniomyces castellii CSIR-Y993; Schwanniomyces alluvius CSIR-Y828; Lodderomyces elongisporus CSIR-Y162; Wingea robertsii CSIR-Y208, CSIR-Y446; Zygosaccharomyces bailii CSIR-Y126; Debaryomyces marama CSIR-Y216; Debaryomyces vanrijiae CSIR-Y960; Schizosaccharomyces pombe CSIR-Y457; Lipomyces starkeyi CSIR-Y205, CSIR-Y158, IGC 3944; Lipomyces kononenkoae CSIR-Y353, IGC 4052; Lipomyces tetrasporus CSIR-Y503.

Endomycetaceae: Endomyces fibuliger CSIR-Y643; Pichia fluxuum CSIR-Y183; Botryoascus synnaedendrus CSIR-Y406; Hansenula dryadoides CSIR-Y649, CSIR-Y650.

Metschnikowiaceae: Metschnikowia reukaufi CSIR-Y13.

Saccharomycodaceae: Hanseniaspora valbyensis CSIR-Y895; Hanseniaspora uvarum CSIR-Y898; Saccharomycodes ludwigii CSIR-Y22, CSIR-Y8.

Cultivation. Stock cultures were maintained on yeast extract/malt extract (YM) (Wickerham, 1951) slants. The strains were cultured under standard conditions for $16 \mathrm{~h}$ at $30^{\circ} \mathrm{C}$ on a rotary shaker at 160 r.p.m. (throw $50 \mathrm{~mm}$ ) in $150 \mathrm{ml}$ conical flasks containing $40 \mathrm{ml}$ YNB medium $\left[80 \mathrm{~g}\right.$ glucose (Merck) and $6.7 \mathrm{~g}$ yeast/nitrogen base $1^{-1}$ 
(Wickerham, 1951)]. Volumes (18 ml) of these cultures (Klett reading $150,640 \mathrm{~nm}$ filter) were then inoculated into $400 \mathrm{ml}$ glucose YNB liquid medium in 11 conical flasks and cultured to stationary phase $(48 \mathrm{~h})$ on the rotary shaker (Dawson \& Craig, 1965). This procedure was repeated three times. The cells were harvested by centrifugation at $8000 \mathrm{~g}$ for $5 \mathrm{~min}$ at $4^{\circ} \mathrm{C}$ and washed three times with cold saline $(0.85 \% \mathrm{NaCl})$, with centrifugation after each washing. The cells were stored at $-15^{\circ} \mathrm{C}$.

Fatty acid analysis. The extraction and preparation of fatty acid methyl esters were done according to the method proposed by Gunasekaran \& Hughes (1980). The final extraction of the fatty acid methyl esters was done with $\mathrm{n}$-hexane. The fatty acid methyl esters were analysed by gas chromatography on a Hewlett Packard Model $5830 \mathrm{~A}$ gas chromatograph equipped with dual flame-ionization detectors. Identification of the esters was based on the comparison of retention times with known standards of C14:0 (myristic acid), C14:1 (myristoleic acid), $\mathrm{C} 16: 0$ (palmitic acid), C16:1 (palmitoleic acid), C18:0 (stearic acid), C18:1 (oleic acid), C18:2 (linoleic acid) and $\mathrm{C} 18: 3$ (linolenic acid) (Serva). Analyses were done using glass columns ( $4 \mathrm{~mm}$ i.d. $\times 1.5 \mathrm{~m}$ ) packed with $5 \%$ diethylene glycol succinate on Chromosorb W (80-100 mesh: Anatech). The flow rate of the carrier gas (nitrogen) was $40 \mathrm{ml} \mathrm{min}^{-1}$ at a column temperature of $160{ }^{\circ} \mathrm{C}$.

Numerical analysis. The Pearson product-moment correlation coefficient, $r$, between any pair of long-chain fatty acids was computed (Pearson \& Hartley, 1958). The resulting matrix of correlation coefficients was converted into a $z$ matrix by Fischer transformation (Rohlf \& Sokal, 1962), and the $z$ values were clustered by the unweighted average pair group method. The $z$ values of all clustering levels were again transformed into $r$ values (Sokal \& Sneath, 1963). All the computations were done at the University of the Orange Free State on a Sperry Univac 1100 computer.

\section{RESULTS}

The similarities of the cellular long-chain fatty acid composition of the 33 strains are presented in Fig. 1. The strains clustered into three major groups. Groups I and II had a similarity (Sokal \& Sneath, 1963) of $r=0.82$ and groups II and III a similarity of $r=0.42$. The mean fatty acid composition with standard deviation for each group is shown in Fig. 2. The statistical interpretation of the results was performed by Student's $t$-test (Schefler, 1979).

Group I. The percentage of oleic acid $(\mathrm{C} 18: 1)$ was higher in this group than in the other groups, while the percentage of linoleic acid $(\mathrm{C} 18: 2)$ was significantly lower than in group II ( $P$ $<0.01$ ).

Group II. The four species included in this group were characterized by the presence of substantial amounts of both oleic acid $(\mathrm{C} 18: 1)$ and linoleic acid $(\mathrm{C} 18: 2)$. The percentage of oleic acid was significantly higher in group I $(P<0.01)$ and that of linoleic acid significantly lower in groups I and III $(P<0.01)$ than in group II.

Group III. This group was characterized by a significantly higher percentage of palmitoleic acid $(\mathrm{Cl} 6: 1)$ than the other groups $(P<0 \cdot 01)$, and a low percentage of linoleic acid $(\mathrm{C} 18: 2)$.

\section{DISCUSSION}

The species in group I (excluding Schizosaccharomyces pombe CSIR-Y457) are placed in the family Saccharomycetaceae by Von Arx (1981). Three subgroups, $(a),(b)$ and $(c)$ could be recognized in group I (Fig. 1). Subgroup (a) consists of species which can ferment glucose (Kreger-van Rij, 1984), while the species in subgroup (b) are not capable of fermenting glucose, with the exception of Schizosaccharomyces pombe CSIR-Y457 (K reger-van Rij, 1984). Subgroup (b) comprises species containing coenzymes Q-9 and Q-10 (Yamada et al., 1973, 1976). Subgroup (a) includes four interbreeding species of Schwanniomyces which were placed in a single taxon, Schwanniomyces occidentalis, by Barnett et al. (1983) and Price et al. (1978). Subgroup (c) comprises three Lipomyces species which contain coenzyme Q-9 (Yamada et al., 1977) and have no fermentation abilities (Kreger-van Rij, 1984).

The species representing group II are, with one exception, grouped under the Endomycetaceae as defined by Von Arx (1981). They contain coenzymes Q-7 and Q-8 (Yamada et al., 1973, 1976). The single strain of Metschnikowia reukaufi, placed in the Metschnikowiaceae by Von Arx (1981), also fell into this group but it had a somewhat higher proportion of palmitoleic acid (C16:1) than the other members of the group.

Group III comprised Hanseniaspora valbyensis (CSIR-Y895), Hanseniaspora uvarum (CSIRY898) and Saccharomycodes ludwigii (CSIR-Y22, CSIR-Y8). Von Arx (1981) placed these 


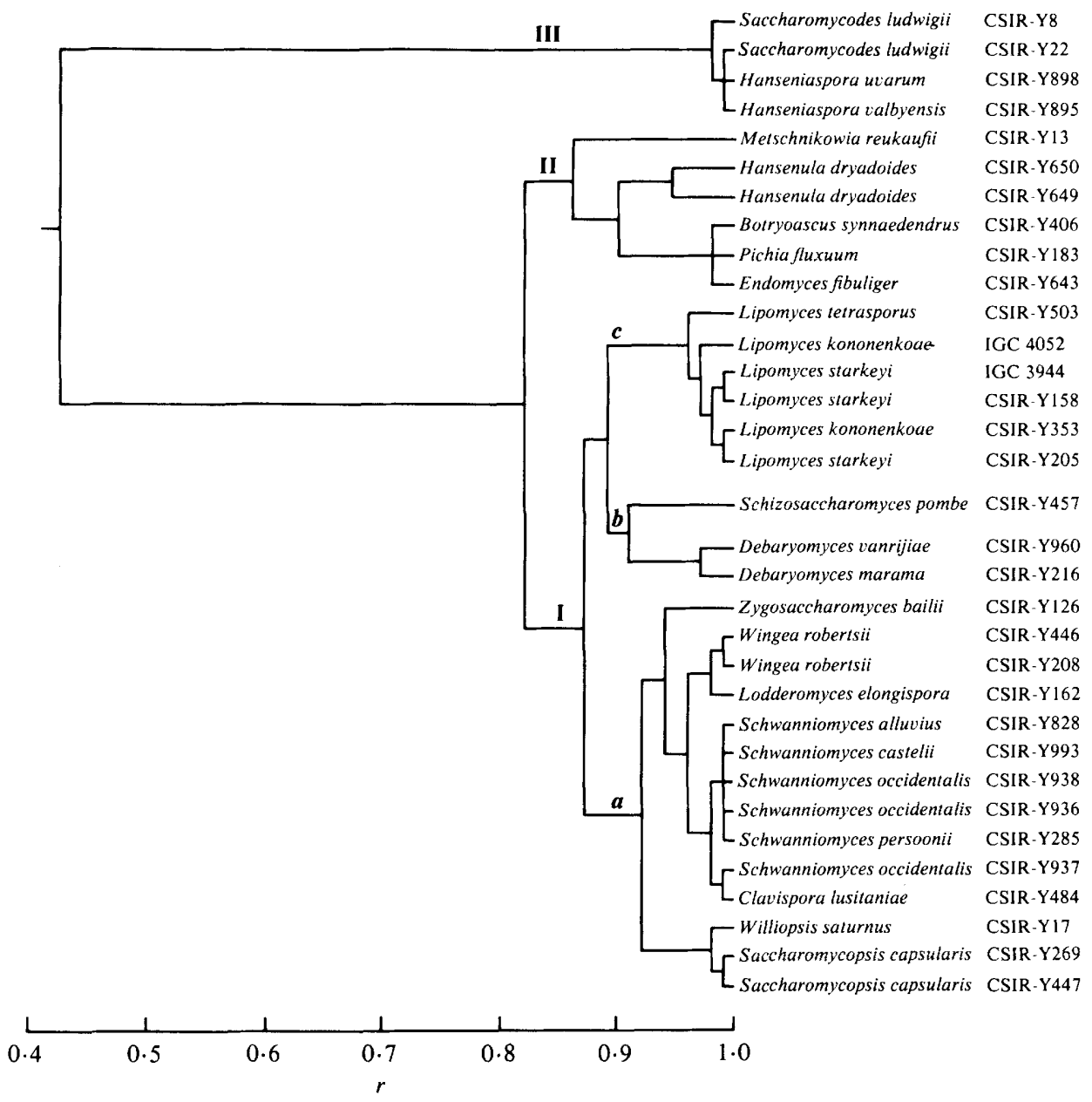

Fig. 1. A dendrogram showing similarity between 33 yeast strains of the order Endomycetales.

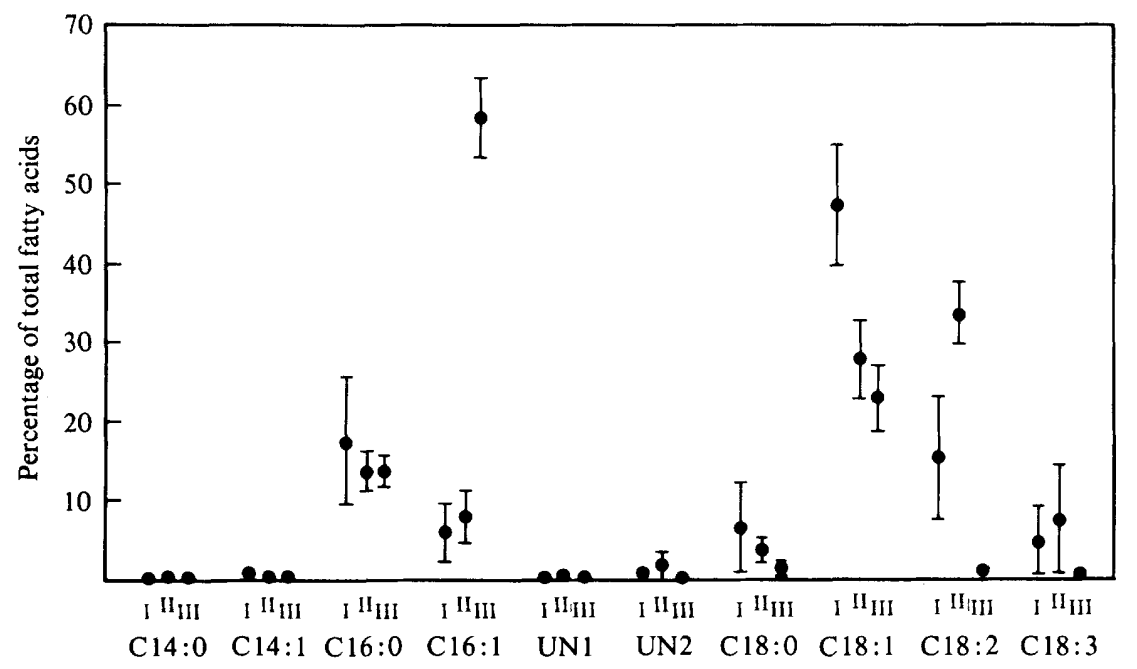

Fig. 2. Mean percentage fatty acid composition and standard deviation (bars) of the strains in groups I, II and III (see Fig. 1). UN1, UN2, unidentified long-chain fatty acids, having retention times of 13.36 and $14.13 \mathrm{~min}$ respectively (the retention time of C16:0 was $10.25 \mathrm{~min}$ ). 
species under the Saccharomycodaceae. The species in this group contain coenzyme Q-6 (Yamada et al., 1980) and can ferment glucose (Kreger-van Rij, 1984). They all reproduce asexually by polar budding (Barnett $e t$ al., 1983).

This study has shown that fatty acid composition can be used to classify yeast strains into groups and subgroups which correspond with the classification system proposed by Von Arx (1981). This work should be extended to include more yeasts to prove the general validity of this method as an additional phenotypic aid in classification.

The authors are indebted to Professor J. P. van der Walt of the CSIR, Pretoria, South Africa, for supplying yeast cultures and giving valuable advice. They would also like to thank Carol Viljoen for excellent secretarial work and P. J. Botes for gas chromatographic assistance.

\section{REFERENCES}

Barnett, J. A., Payne, R. W. \& Yarrow, D. (1983) Yeasts: Characteristics and Identification. New York \& Cambridge: Cambridge University Press.

Dawson, P. S. S. \& Craig, B. M. (1965). Lipids of Candida utilis: changes with growth. Canadian Journal of Microbiology 12, 775-785.

Gangopadhyay, P. K., Thadepalli, H., Roy, I. \& ANSARI, A. (1979). Identification of species of Candida, Cryptococcus and Torulopsis by gas-liquid chromatography. Journal of Infectious Diseases 140, 952-958.

Gunasekaran, M. \& Hughes, W. T. (1980). Gasliquid chromatography: a rapid method for identification of different species of Candida. Mycologia 72, 505-511.

Kaneko, H., Hosohara, M., Tanaka, M. \& Itoh, T. (1976). Lipid composition of 30 species of yeasts. Lipids 11, 837-844.

Kock, J. L. F., Lategan, P. M., Botes, P. J. \& VILJOEN, B. C. (1985). Developing a rapid statistical identification process for different yeast species. Journal of Microbiological Methods 4, 147-154.

KREGER-VAN RIJ, N. J. W. (1984). The Yeasts: $a$ Taxonomic Study. Amsterdam: Elsevier.

Moss, C. W., Shinoda, T. \& Samuels, J. W. (1982). Determination of cellular fatty acid compositions of various yeasts by gas-liquid chromatography. Journal of Clinical Microbiology 6, 1073-1079.

Pearson, E. S. \& Hartley, H. O. (1958). Biometrika Tables for Statisticians, vol. 1. Cambridge: Cambridge University Press.

Price, C. W., Fuson, G. B. \& Phaff, H. J. (1978). Genome comparison in yeast systematics: delimitation of species within the genera Schwanniomyces,
Saccharomyces, Debaryomyces and Pichia. Microbiological Reviews 42, 161-193.

RoHLF, F. J. \& SoKAL, R. R. (1962). The description of taxonomic relationships by factor analysis. Systematic Zoology 11, 1-16.

SCHEFLER, W. C. (1979). Statistics for the Biological Sciences, 2nd edn. London: Adison-Wesley.

SoKal, R. R. \& SNEath, P. H. A. (1963). Principles of Numerical Taxonomy. London: W. H. Freeman.

Von ARX, J. A. (1981). The Genera of Fungi Sporulating in Pure Culture. Braunschweig: J. Cramer.

WiCKerhaM, L. J. (1951). Taxonomy of Yeasts. Technical Bulletin no. 1029, United States Department of Agriculture.

Yamada, Y., ARimoto, M. \& Kondo, K. (1973). Coenzyme $Q$ system in the classification of the ascosporogenous yeast genus Schizosaccharomyces and the yeast-like genus Endomyces. Journal of General and Applied Microbiology 19, 353-358.

Yamada, Y., ARImoto, M. \& Kondo, K. (1976). Coenzyme $Q$ system in the classification of apiculate yeasts in the genera Nadsonia, Saccharomycodes, Hanseniaspora, Kloeckera, and Wickerhamia. Journal of General and Applied Microbiology 22, 293-299.

Yamada, Y., ARIMOTO, M. \& Kondo, K. (1977). Coenzyme $Q$ system in the classification of some ascosporogenous yeast genera in the families Saccharomycetaceae and Spermophthoraceae. Antonie van Leeuwenhoek 43, 65-71.

Yamada, Y., Takinami-NaKamura, H., Tahara, Y.\& SMITH, M. T. (1980). The coenzyme Q system in the classification of the ascosporogenous yeast genus Dekkera and the asporogenous yeast genus Brettanomyces. Antonie van Leeuwenhoek 46, 595-599. 